\title{
Movement patterns of Sanderling (Calidris alba) in the East Asian-Australasian Flyway and a comparison of methods for identification of crucial areas for conservation
}

\author{
Simeon Lisovski ${ }^{\mathrm{A}, \mathrm{D}}$, Ken Gosbell ${ }^{\mathrm{B}}$, Maureen Christie ${ }^{\mathrm{B}}$, Bethany J. Hoye ${ }^{\mathrm{A}}$, Marcel Klaassen ${ }^{\mathrm{A}}$, \\ lain D. Stewart ${ }^{\mathrm{B}}$, Alice J. Taysom ${ }^{\mathrm{C}}$ and Clive Minton ${ }^{\mathrm{B}}$ \\ A Deakin University, School of Life and Environmental Sciences, Centre for Integrative Ecology, \\ 75 Pigdons Road, Geelong, Vic. 3220, Australia. \\ ${ }^{B}$ Victorian Wader Study Group, c/o 165 Dalgetty Road, Beaumaris, Vic. 3193, Australia. \\ ${ }^{\mathrm{C}}$ Applied Ecology Research Group, College of Engineering and Science, Victoria University - Footscray Park \\ Campus, PO Box 14428, Melbourne MC, Vic. 8001, Australia. \\ ${ }^{D}$ Corresponding author. Email: simeon.lisovski@gmail.com
}

\begin{abstract}
Worldwide, most populations of migratory shorebirds are in jeopardy, none more so than those of the East Asian-Australasian Flyway (EAAF). In order to preserve these highly mobile species a detailed understanding of their use of feeding and resting sites along the flyway is required. In this study we used light-level geolocators and new analytical tools to reveal individual breeding locations and migration routes of 13 Sanderlings (Calidris alba) that spend their nonbreeding season in South Australia. We then used these individual migration routes to identify the timing and location of important stopping areas and compared this with assessments based on resightings of leg-flagged birds and count data. During both northward and southward migration, Sanderlings were found to make extensive use of five main areas of the Chinese coastline, the Yellow Sea and the northern end of the Sakhalin Peninsula. Insights gained from the individual migration routes highlight inherent biases in using only count and resighting data to identify important feeding and resting sites along the Flyway. These findings suggest that data on individual movements may be crucial to effective conservation planning of shorebirds in the EAAF and elsewhere in the world.
\end{abstract}

Additional keywords: banding data, bird counts, bird migration, conservation planning, light-level geolocation, MCMC path estimation, migratory connectivity, resightings.

Received 20 April 2015, accepted 1 December 2015, published online 10 March 2016

\section{Introduction}

Animal migration is thought to have evolved in response to spatiotemporal variation in the abundance of resources and threats (e.g. Alerstam et al. 2003; Dingle and Drake 2007; McKinnon et al. 2010). Despite the immense costs involved in performing regular, and often long-distance, journeys, migration is a common and widespread phenomenon in the animal kingdom (Dingle and Drake 2007). In particular, most species of shorebirds are migratory (Kirby et al. 2008), some of which undertake migratory movements of up to $30000 \mathrm{~km}$ per year (e.g. Harrington 2001; Gill et al. 2009; Minton et al. 2010).

In order to meet the physiological demands of migration most migratory birds partition their journey into a series of flights interrupted by periods of intense feeding and resting (Piersma 1987; Colwell 2010). Consequently most migratory birds depend on a network of suitable feeding and resting sites along their flyway for successful migration and survival. This reliance on multiple sites is thought to render migratory species highly susceptible to changes on a local and global scale (Piersma and
Baker 2000; Runge et al. 2014) and, as a result, migratory populations across a wide range of taxa have declined in recent decades (Wilcove and Wikelski 2008). Migratory shorebirds in all global flyways, and especially the East Asian-Australasian Flyway (EAAF), are emblematic of these declines (Bamford et al. 2008; Amano et al. 2010).

Effective protection of highly mobile species is predicated on detailed understanding of how migrants make use of their flyway, and hence the areas and sites that are crucial for conservation (Holdo and Roach 2013; Runge et al. 2014). Counts of birds and bird-banding programs, including leg-flagging and subsequent resightings, have traditionally been used to develop an initial understanding of migratory movements and to initiate conservation measures (e.g. Bamford et al. 2008; Minton et al. 2011). The effectiveness of these methods is highly dependent on the spatiotemporal distribution of observers. Accurate tracks from individual migratory shorebirds equipped with satellite transmitters have revealed considerably more detail on migration schedules and routes than traditional methods (Gill et al. 2009; 
Battley et al. 2012). Despite the ongoing development of increasingly lighter devices, the use of satellite transmitters is restricted to a small number of species of larger body mass. Light-level geolocators (hereafter geolocators) are considerably lighter than satellite transmitters ( $<1 \mathrm{~g}$; Bridge et al. 2011), and therefore provide the opportunity to track smaller migratory birds and greatly expanding the number of species that may be studied. Initial application of geolocators to shorebirds has provided valuable information on the migratory movements of several species using the EAAF (e.g. Minton et al. 2010, 2013). However, our ability to make detailed and accurate descriptions of migratory movements based on geolocator data has, so far, been hindered by coarse spatial resolution (Lisovski et al. 2012) and the inability to determine spatial location during the equinoxowing to equal daylength across the globe - and during the breeding season -owing to constant daylight on the Arctic breeding grounds of these shorebirds. Consequently, the identification of critical sites used by large proportions of a population has thus far remained a key challenge to conservation along the EAAF, but the ongoing development of geolocator devices and processing tools offers significant potential for progress.

In this study, we used new-generation light-level geolocators that record the full light range, in combination with recently developed analytical tools, to determine individual movement tracks and associated uncertainty estimates, providing detailed understanding of migration patterns of Sanderlings (Calidris $a l b a)$ in the EAAF. Sanderlings have a worldwide distribution and perform some of the longest distance migrations yet recorded (Lanting 1984; Reneerkens et al. 2009; Minton et al. 2013). The species breeds in the Arctic along the northern coast of European and Siberian Russia, in parts of Alaska, in the Canadian Arctic and in northern Greenland. During the nonbreeding season Sanderlings use a wide range of wintering sites, including around $40-45^{\circ} \mathrm{N}$ in western Europe, North America and Asia (MacWhirter et al. 2002), and to the southern tips of South America, Africa and Australia.

Our aims were twofold: (1) to provide a detailed description of the biannual migration of Sanderlings in the EAAF; and (2) to compare three different methods - count data, leg-flag resightings, and individual geolocator tracks - for identifying critical areas for shorebird conservation in the EAAF. Geolocator tracks were processed and compared using the most frequently used method, hereafter referred to as the 'simple threshold method' (Lisovski and Hahn 2012), and a recently developed and more sophisticated Bayesian framework using Markov Chain Monte Carlo methods to estimate location posterior, hereafter referred to as 'MCMC path estimates'. In describing the movements of Sanderlings along the EAAF, we further aimed to show that the recent advances in light-level geolocation allow us to (1) reveal detailed migration schedules and routes; (2) estimate the location of the high Arctic breeding sites of the species; and (3) describe and quantify the degree of within-population migratory connectivity over the annual cycle.

\section{Methods}

Animal capture and tracking data

A total of 44 light-level geolocators (Intigeo-W65, Migrate Technology Ltd, Cambridge, UK) were deployed in March
2012 at Canunda National Park, in south-eastern South Australia $\left(140^{\circ} 11^{\prime} \mathrm{E}, 37^{\circ} 37^{\prime} \mathrm{S}\right)$ under approval from the South Australian Department of Environment, Water and Natural Resources. Canunda National Park is an important wintering site for Sanderlings during the boreal winter (austral summer), with typically between 200 and 400 individuals present from October to April each year (Bamford et al. 2008). Sanderlings were caught, using cannon nets, in a single catch, on the ocean beach where they forage and roost. A geolocater was placed on the left tibia of each bird. The geolocater was fastened to a leg-flag (made from a 'darvik' PCV sheet) using Kevlar thread reinforced with Araldite resin cement. To comply with the Australian Bird and Bat Banding Scheme for South Australia, two additional flags were employed (orange above yellow). In order to individually identify birds on which we deployed geolocators, we used an engraved flag from the orange (upper) flag. This flag was $0.6 \mathrm{~mm}$ thick, bi-coloured material with the orange engraved through to reveal the black below. Geolocators weighed $0.65 \mathrm{~g}$, making the total weight, including the flag, $\sim 1 \mathrm{~g}$. This represents $<2 \%$ of the mean (lean) body mass of Sanderlings (for measurements, see supplementary material S1, available online). Based on multiple reports it appears that shorebirds readily adapt to carrying geolocators on their legs and that the device has no significant effect on annual survival (e.g. Conklin et al. 2010; Niles et al. 2010). A total of 14 geolocators were retrieved (32\%), 13 from birds caught at the site where they had been first caught and geolocators deployed, and one from a bird shot in Sakhalin, eastern Siberia, in May 2013. Retrieval rates of geolocators in other shorebird studies conducted by the Victorian Wader Study Group and the Australasian Wader Studies Group varied between 10\% (Great Knot (Calidris tenuirostris)) and 50\% (Ruddy Turnstone (Arenaria interpres)). These retrieval rates reflect the ability to detect and catch the individuals as well as their site-fidelity and not their actual probability of survival. Other individuals carrying geolocators have been seen occasionally at or near this location, including one as recently as September 2016. The bird shot in Siberia during northward migration in 2013 also indicates that the detection rate is not $100 \%$ because the geolocator data revealed that this individual spent the non-breeding season of 2012 near the deployment site. All individuals, except the bird shot in Siberia (B013), were sexed molecularly, using the primers P8 and P2 according to the method described by Griffiths et al. (1998). We used a principal component analysis based on morphological measurements to assign B013 the status of female with a probability of 0.7 (see S1 in Supplementary material).

\section{Analysis of geolocator data}

Light-intensity recordings from geolocators were used to first estimate the breeding sites of each individual and subsequently, using the derived breeding site position, to estimate the full migration path.

\section{Breeding sites}

Sanderlings breed at high Arctic latitudes (Lappo et al. 2012) and thus experience constant daylight during this part of their annual cycle. Conventional methods to estimate positions from light-intensity recordings over time (i.e. geolocation by light) 
usually fail to produce reliable position estimates under conditions of 24-h daylight as the light sensor generally does not record any variation in light intensity through the day (Lisovski et al. 2012). However, the light sensor in the geolocators used in this study recorded the full range of light intensities for each day, allowing the breeding location to be estimated. We developed a template-fit analysis to estimate the positons of the breeding sites. For each individual, light-intensity records from the deployment site in Australia, recorded on the bird during the stationary period after deployment or before retrieval of the device, were used to generate a calibration curve of light intensity as a function of zenith angles, using astronomical functions within the R package SGAT (Wotherspoon et al. 2013). This calibration curve allowed generation of expected light at any location for a given time or zenith angle. Using the individual, geolocator-specific calibration curves, predictions were made on the temporal variations in daily light intensity for the entire breeding season for every $50 \times 50-\mathrm{km}$ grid-cell across the entire Russian Arctic. Next, the predicted light values were compared with the observed light data. We calculated the percentage of single light-intensity recordings that exceeded the predicted values within each grid-cell. Observations can only have been recorded within grid-cells where $100 \%$ of the observed light-intensity values were below the predicted values. This approach assumes that birds were resident during the entire breeding period. To correct for potential travel after arrival at or before departure from the Arctic we excluded observations from three days after arriving in the region experiencing 24-h daylight and three days before departure from that region. In the best-case scenario, when light-intensity measurements are little influenced by shading of any kind, the $100 \%$ likelihood contour line plotted across the potential breeding area is characterised by a v-shape (or u-shape) with the highest likelihood slightly above the minima of this contour line (see supplementary material S2). We selected the closest position on land to this lowest latitudinal position above the $100 \%$ contour line. From data recorded at the deployment and retrieval site in South Australia we estimated geolocation error to be $<200 \mathrm{~km}$. However, since the variation in elevation angle of the sun at the breeding grounds is low and signal-to-noise ratio high (owing to incubation and habitat) we expect location accuracy of the estimated breeding sites to be up 100-300 km lower (for more details, code and explanations see S2 in Supplementary material).

\section{Migration pathway}

Daily positions, and hence migration pathways, for each individual were estimated from raw light-level data using the threshold method of estimating positions based on sunrise and sunset events (Lisovski et al. 2012). Daily sunrise and sunset times as well as initial positions based on the simple threshold method were calculated using the R package GeoLight (Lisovski and Hahn 2012). A light-intensity threshold of 0.8 was used for all individuals. The corresponding zenith angle was defined from sunrise and sunset times recorded while the birds were at the deployment site. The defined zenith angle varied between individuals and ranged from 93.4 to 96.5 . To derive more accurate positions, we used a Bayesian framework that incorporates the observed sunrise and sunset times together with prior knowledge of Sanderling behaviour to provide location estimates with associated measurements of uncertainty. The $\mathrm{R}$ package SGAT (Sumner et al. 2009; Wotherspoon et al. 2013) uses MCMC simulations that permit a spatial probability mask, prior definition of the error distribution of twilight events (twilight model) and plausible flight-speed values (behavioural model), which collectively allowed us to refine the tracks derived from the sunrise and sunset times (for detailed description of the model assumptions, see Sumner et al. 2009). The 'spatial probability mask' is based on the premise that, during migration, Sanderlings are most commonly found on coastal sandy beaches, although they may also occur on tidal mudflats and the shores of lakes and rivers. Estimated positions were therefore considered to be more likely if close to a shoreline and independent of the habitat type: the relative probability was assumed to decrease exponentially (from 4 to 1 ) with increasing distance from the shoreline, using the equation

$$
1+5 \times \exp \left(-(\mathrm{d} / 50000)^{3}\right)
$$

We used a spatial shoreline dataset with a $1: 75000$ scale (http:// www.ngdc.noaa.gov/mgg/shorelines/shorelines.html, accessed 1 September 2014). For the 'twilight model', the discrepancy between observed and expected times of twilight was assumed to follow a log-normal distribution. For sunrise, positive values correspond to an observed sunrise occurring after the expected time of sunrise, whereas for sunset, positive values correspond to an observed sunset occurring before the expected time of sunset. We chose a conservative prior (log-normal distribution, with meanlog $=1.65, \operatorname{sdlog}=0.9$ ) since error in twilight detection potentially varies greatly over the annual cycle. For the 'behavioural model', we assumed that migratory shorebirds perform stepwise migrations, with fairly long staging periods between periods of movement (Piersma 1987; Warnock 2010). We modelled flight-speed (ground-speed) using a gamma distribution ( shape $=0.7$, scale $=0.05$ ) assuming that the speed with the highest probability was $<1$ (i.e. the bird is most likely to be stationary at any given time), and that maximum flight speeds up to $80 \mathrm{~km} \mathrm{~h}^{-1}$ were likely to occur during migration (Pennycuick et al. 2013). For each individual we used these parameters and started by drawing an initial 10000 samples for burn-in and tuning of the proposal distribution. One sample reflects one set of positions between each twilight event along the migration path. The proposal distribution is the conditional probability here the spatial probability distribution of the individual - that is calculated after all available information was taken into account. A further 40000 samples were drawn to visually evaluate chain convergence. A final draw of 5000 samples was then generated to describe the posterior distribution. (R-code for individual location estimation is available from the authors upon request.)

\section{Analysis of migratory movements}

We used the median of the posterior distribution as our estimate for the most likely daily position of each individual and hence their most likely migration path. We evaluated the timing of migration and whether the individual was moving on a given day during migration using a first-passage-time(FPT) analysis: the FPT describes the time required for an individual to cross a circle with a radius of $500 \mathrm{~km}$ (Fauchald and Tveraa 2003). In 
a second step, FTP was used to identify periods of residency periods of stable FTP within the defined radius. All posterior distributions, 5000 positions per day per individual, were combined to calculate the aggregated time the tracked population spent in each grid-cell. Furthermore, those posterior distributions were used to analyse migratory connectivity and, in particular, the spatial spread of the individuals from the tracked population over time resulting from the temporal synchrony within the population (Bauer et al. 2015). To quantify the within-population connectivity, a minimum convex hull was generated around the 0.6 and 0.95 quartile contour lines - the space that includes $60 \%$ and $95 \%$ of the samples forming the posterior distribution across five-day intervals using the $m c p$ function of the R package adehabitatHR (Calenge 2006). The area where the convex hulls and the Flyway, defined as the 0.4 quartile contour line of all posterior distributions from all individuals, overlap were used to quantify the spatial spread of the population for each five-day period.

\section{Resightings of leg-flags}

To compare leg-flag resightings with our tracking results we used resightings of Sanderlings originally flagged on the coast of south-eastern South Australia, where the geolocator devices were deployed. Leg-flags placed on shorebirds at this site are orange over yellow, and a total of 3638 Sanderlings have been flagged. Resightings of leg-flags from across the Flyway have been drawn from the Australasian Wader Studies Group database (http://www.awsg.org.au/flagging.php, accessed 1 September 2014). We further limited our use of resightings to those reported during the migration periods (15 April - 1 July for northward migration,; 1 July - 1 November for southward migration). Flag sightings were aggregated on a $500 \times 500-\mathrm{km}$ spatial grid.

\section{Bird counts}

Counts of Sanderling were extracted from estimates of shorebird populations within the EAAF based on a review of count data in Bamford et al. (2008, pp. 91-93). This report provides spatial information on counts per species and for the periods of northward migration, southward migration, breeding and non-breeding, between 1979 and 2003. Here we used the count data from identified internationally important sites that regularly support $1 \%$ of the individuals of a population of one species or subspecies (Criterion 6 of the Ramsar Convention (Ramsar Convention Bureau 1971)). Maximum counts were aggregated on a $500 \times$ 500-km spatial grid.

\section{Results}

\section{Breeding sites}

The estimated positions of breeding sites spanned an area from the New Siberian Islands of eastern Siberia, $300 \mathrm{~km}$ south to the Siberian mainland of Russia and $1300 \mathrm{~km}$ west to the Taimyr Peninsula (Fig. 1). The highest aggregation of estimated breeding sites was on the New Siberian Islands.

\section{Migration pathways}

Thirteen individuals were recorded performing a complete migration cycle from the deployment site in South Australia to the Arctic breeding grounds and back. Detailed individual migration itineraries are shown in S3 in Supplementary material. Only one individual (ID2030) did not perform a complete migration; this individual left on 15 May 2012, made an extended stopover of 35 days in Borneo and another of 35 days in the area of Hainan Island, southern China before returning to Australia. We excluded this individual from all further analyses.

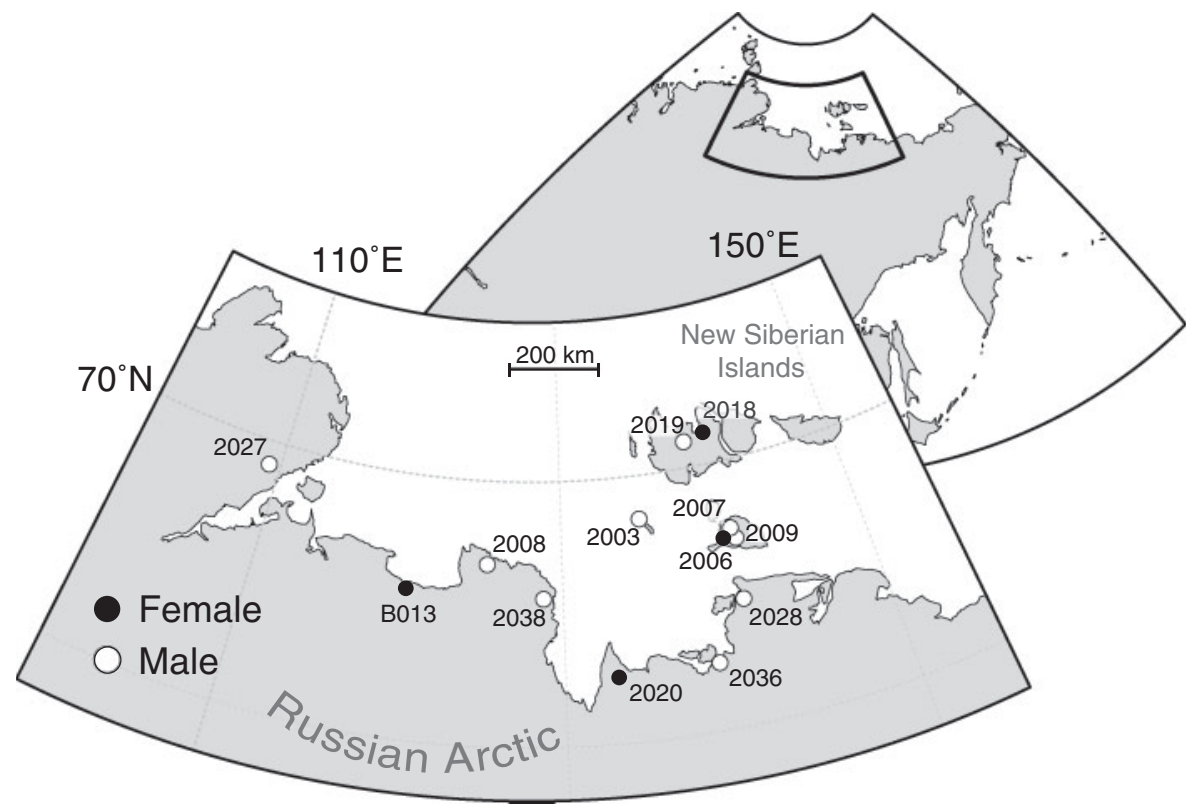

Fig. 1. Estimated breeding locations of tracked Sanderlings (black dots $=$ females; white dots $=$ males; numbers $=$ bird IDs), based on light-intensity records (light-level geolocators). The locations are estimates and are therefore associated with an error (see Methods and Supplementary material S2). 


\section{Northward migration}

After deployment with geolocators, the Sanderlings remained at Canunda National Park until departure for their first migratory leg between 26 April and 10 May 2012 (mean date of departure s.d.: population, 2 May \pm 4.5 days; females, 3 May \pm 5 days; males, 1 May \pm 4 days; Fig. $2 b$ ). In general, individuals made a single long-distance flight from South Australia, across the Equator, to the coasts of Vietnam and China. The coasts of Hainan Island, central China, Taiwan and the Yellow Sea were used intensively for extended stopovers (Fig. 3a). All but one individual (ID2007) also made an additional stopover along the coast of the Sea of Okhotsk, at the northern end of Sakhalin Island. Sanderlings arrived on their breeding sites between 5 and 16 June 2012 (mean date \pm s.d.: population, 11 June \pm 6 days; females, 11 June \pm 5 days; males, 10 June \pm 6 days; Fig. 2b). Northward migration, on average, was completed within 40 days of departure, ranging from a maximum of 48 days (ID2003) to a minimum of 35 days (ID2007).

\section{Southward migration}

All tracked individuals left their breeding sites between 13 July and 22 August 2012 (mean dates \pm s.d.: population, 23 July \pm 11 days; females, 1 Aug \pm 19 days; males, 19 July \pm 6 days; Fig. 2c) after staying between 32 days (ID2009) and 66 days (ID2018) in their breeding areas. Like northward migration, all but one individual (ID2006) used the coast of the Sea of Okhotsk as the first major stopover site after crossing the Arctic Circle (Fig. 3); in contrast, ID2006 used an inland route via Mongolia before stopping on the coast of central China and Taiwan. Most individuals had subsequent stops along the coasts of China, Taiwan and Korea, although considerably fewer individuals visited the Yellow Sea during southward compared with northward migration. In contrast to northward migration, all individuals made at least one additional stopover in tropical or subtropical regions (Philippines, Indonesia and Malaysia) before returning to Australia. Furthermore, more than half of the individuals (7) used at least one stopover site on the Australian continent before returning to, or close to, Canunda National Park. Sanderlings arrived at these wintering sites between 20 September and 12 November 2012 (mean date \pm s.d.: population, 9 October \pm 27 days; females, 8 October \pm 28 days; males, 9 October \pm 17 days; Fig. $2 c$ ). The timing of return of males and females was almost the same even though, on average, females left the breeding grounds $c$. 2 weeks later than males. Southward migration, on average, was completed in 78 days, ranging from a maximum of 108 days (ID2038) to a minimum of 57 days (ID2019).

\section{Resightings of leg-flags}

Until September 2014, there had been 488 resightings of the 3638 individual Sanderlings banded in south-eastern South Australia reported during the migratory period. Of these, 208 were recorded during northward migration and 280 during southward migration. On northward migration, most resightings were in the Yellow Sea region $(n=137 ; 66 \%)$. Another 26 resightings $(12 \%)$ were from the northern part of Sakhalin Island, Russia, and 25 (12\%) from the coast of central China and Taiwan. During southward migration only one resighting was recorded within the Yellow Sea. During southward migration, most resightings were instead from Japan $(n=145 ; 55 \%)$, along with resightings from the northern end of Sakhalin Island, Russia, $(n=31 ; 11 \%)$ and the coasts of central China and Taiwan $(n=32 ; 11 \%)$.

\section{Count data}

After collating the maximum counts of Sanderlings from all internationally important sites on a $500 \times 500-\mathrm{km}$ grid, we retained a total of 12 grid-cells: seven from the period of northward migration and 11 from the period of southward migration. Two areas adjacent to the geolocator deployment site in southeastern Australia, two areas within the Yellow Sea (Yenchenk National Nature Reserve and Linghekou, China) and three areas in Japan (multiple sites in central and southern Japan) and southern South Korea (Nakdong Estuary) were identified for northward migration based on counts. For southward migration, five additional areas of importance were identified: the northern end of Sakhalin Island (Sakhalinsky Bay, Russia), the southeastern Yellow Sea (Kum Estuary, South Korea), two in northwestern Australia (Roebuck Bay and Eighty Mile Beach) and one in Tasmania (Blanchet Point).
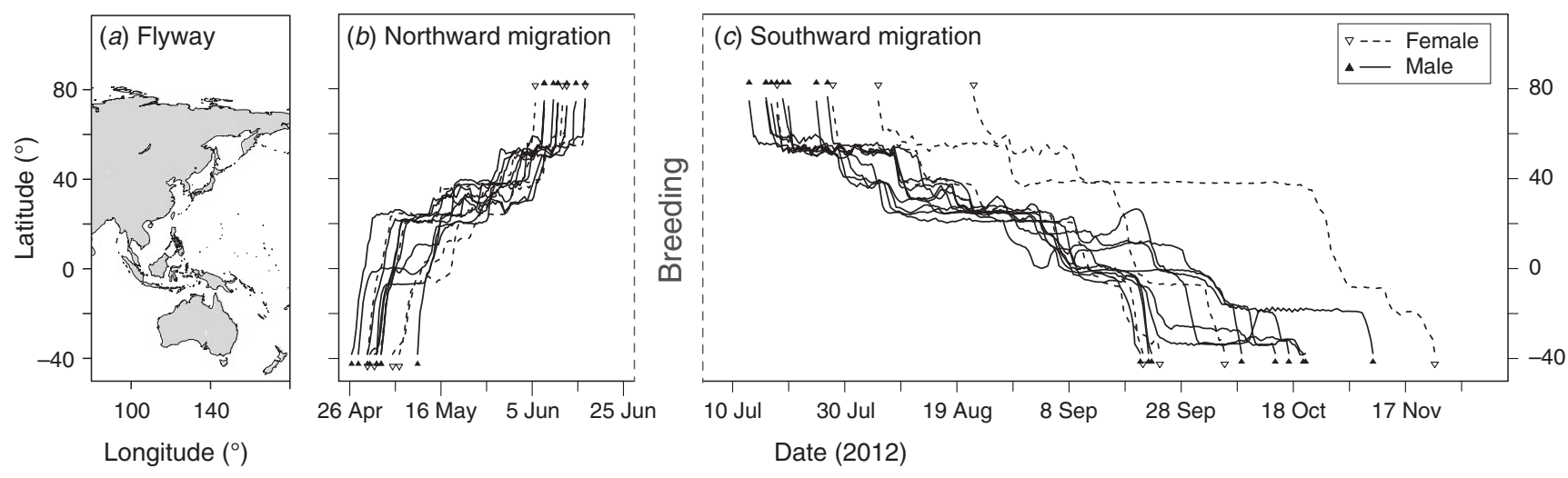

Fig. 2. (a) The East-Asian Australasian Flyway and the latitudinal movement of the 13 Sanderlings tracked using light-level geolocators over time for (b) northward migration and $(c)$ southward migration. 

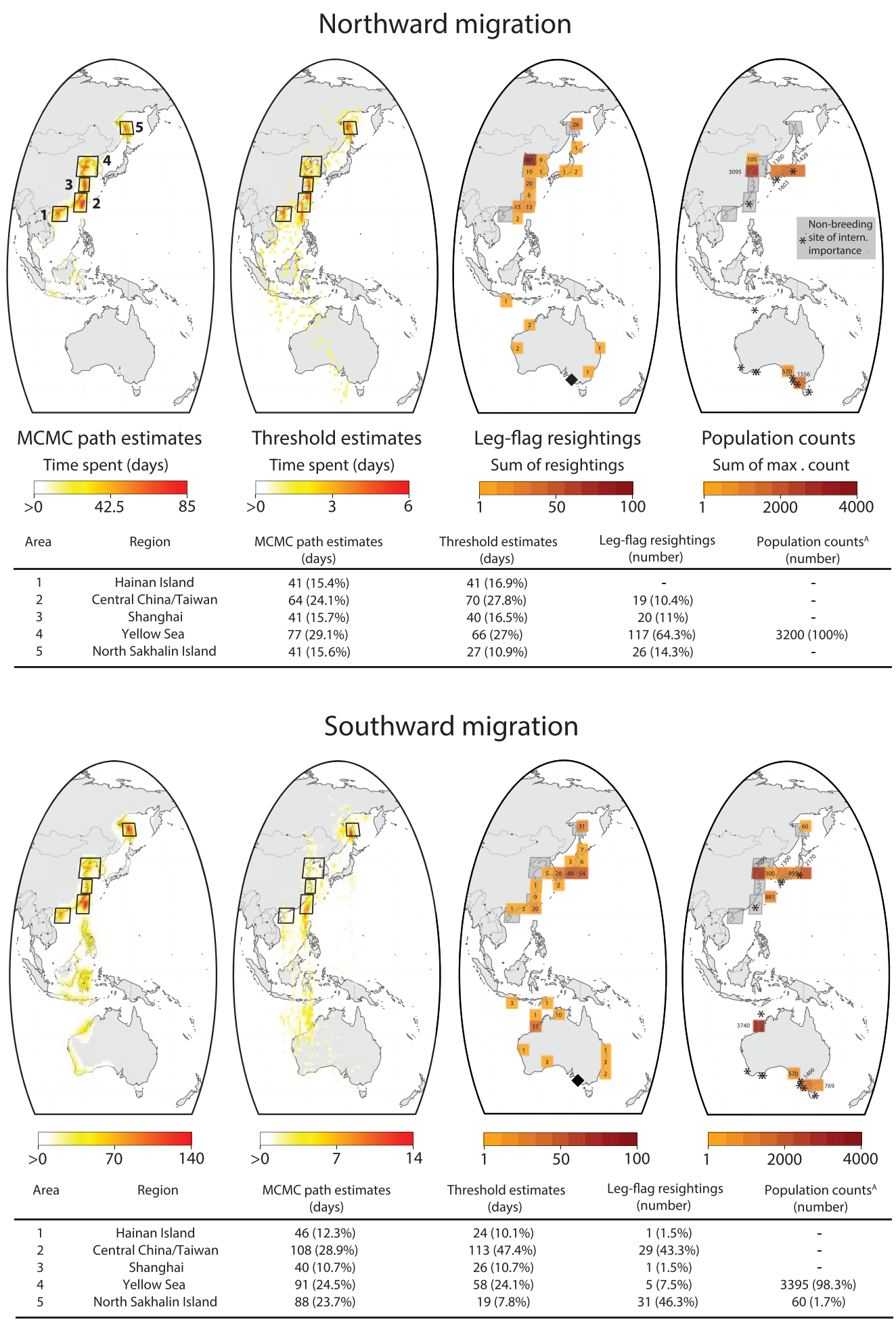

A Population counts within sites of international importance (source: Bamford et al. (2008))

Fig. 3. Comparison of methods for identifying important stopover areas during Sanderling migration. Days spent at each area (bold numbers in Markov Chain Monte Carlo (MCMC) path estimation map) during northward (upper panel) and southward migration (lower panel) are tabulated for two analyses of 13 individual birds tracked using light-level geolocators, as well as the sum of maximum counts (numbers in population count maps) and leg-flag resightings (numbers in leg-flag resighting maps). Percentage values indicate the relative proportion of time spent, all resightings or all counts across all areas, with bold values representing the maximum value for each method. Maps represent time spent for geolocation methods on a $100 \times 100-\mathrm{km}$ grid, and the sum of leg-flag resightings or maximum counts on a $500 \times 500-\mathrm{km}$ grid. 


\section{Comparison of methods for identifying important sites}

Based on the merged posterior distributions of all individual MCMC path estimates, five areas could be identified as being used extensively by the tracked individuals and are therefore classified as areas of major importance. The number of days spent within these areas based on the MCMC path estimates, simple threshold estimates, leg-flag resightings and the sum of maximum Sanderling counts are shown Fig. 2 (within included tables). Although the relative number of days spent between the important areas are concordant between the two different geolocator analysis methods, the leg-flag resightings and bird counts overestimated the use of certain areas by the population (e.g. southern and central Japan) and underestimated or even omitted the use of other areas (e.g. the coastlines of central China and Taiwan; Fig. 3).

\section{Spatiotemporal patterns of migratory connectivity}

Before departure on northward migration, the spatial spread across the population of tracked individuals was low $(60 \%$ convex hull: $1.5^{11}-2.5^{11} \mathrm{~km}^{2} ; 90 \%$ convex hull: $1.3^{12}-1.9^{12} \mathrm{~km}^{2}$ ) and hence the connectivity within the population was high. With the onset of northward migration, spatial spread increased considerably, reaching a maximum of $1.4^{13}-1.9^{13} \mathrm{~km}^{2}(60 \%$ and $90 \%$ convex hulls) between 3 and 8 May (Fig. $4 a$ ). The area subsequently decreased, to $1.6^{12}-7.8^{12} \mathrm{~km}^{2}$, between 23 and 28 May (Fig. 4b), before increasing again to $5.8^{12}-1^{13} \mathrm{~km}^{2}$ between 2 and 7 June, shortly before the arrival of Sanderlings on the breeding grounds (where the population spread over $5^{11}-1.9^{12} \mathrm{~km}^{2}$ ). Soon after the onset of southward migration, the area used by the Sanderlings increased, peaking at $1.6^{13}$ $2.3^{13} \mathrm{~km}^{2}$ between 25 and 30 September (Fig. $4 b$ ). Thereafter, the area used steadily decreased until the population returned to the fairly small area around the deployment site in South Australia.

\section{Discussion}

\section{Comparison of methods for identifying important sites}

When identifying areas of importance for the conservation of highly mobile species, several methods are frequently used. Our results for Sanderlings suggest that although individual tracking methods, leg-flag resightings and bird counts show considerable overlap, critical detail may be lost when relying on the latter two more traditional methods alone. All four methods assessed here invariably identified the coastline of the Yellow Sea as the major stopover area for Sanderlings during northward migration, and both geolocator data and leg-flag resightings indicated extensive use of a large swathe of the central Asian coastline. All methods also highlighted the use of the West Australian coastline as Sanderlings returned to their wintering sites, and that these areas were skipped during northward migration. Indeed, our results suggest that areas of importance to the population may by underestimated or even missed when assessments are based solely on on-the-ground observations. Although several clear areas of importance coincided between both geolocator analysis methods, the population counts and leg-flag resightings showed substantial differences. Critically, the importance of five areas, notably those in tropical and subtropical

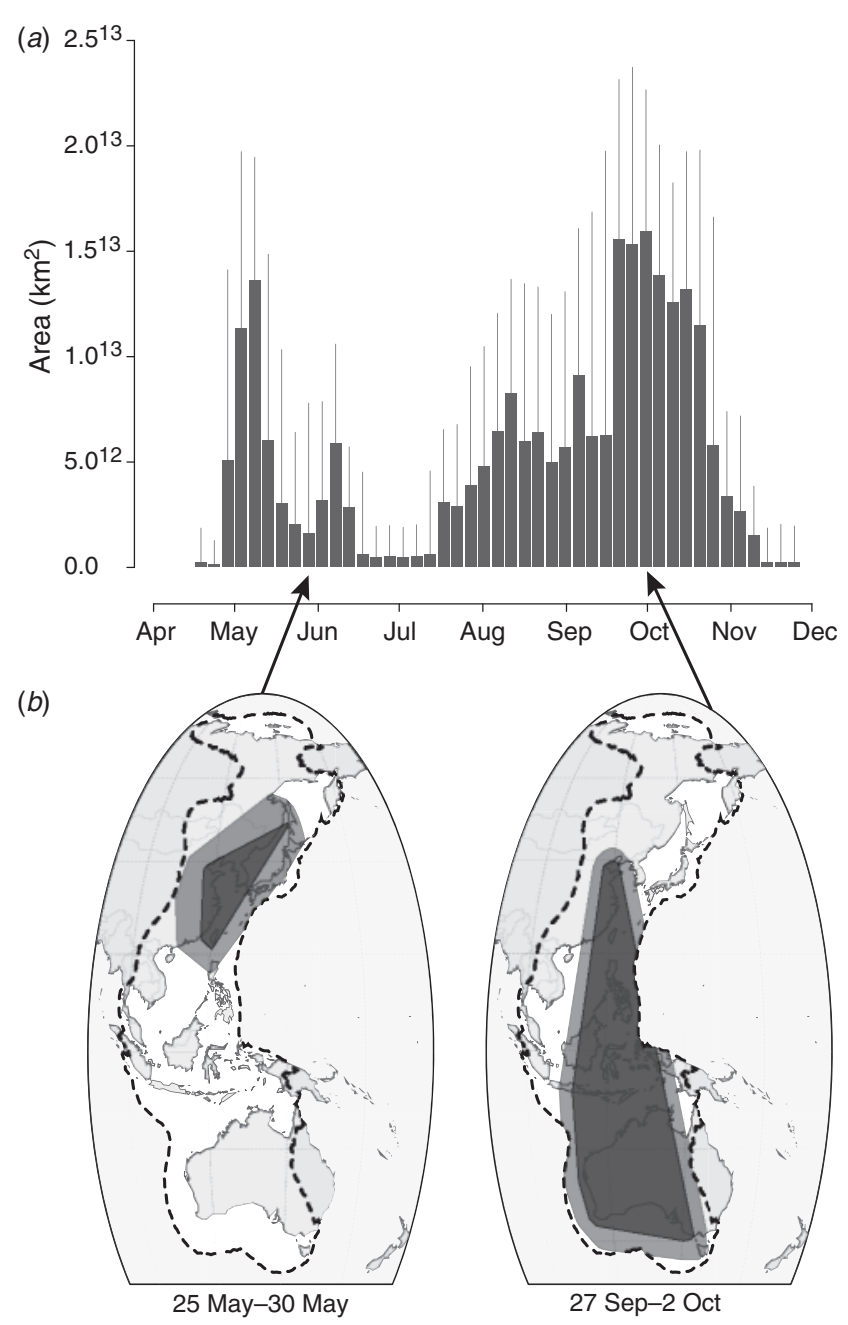

Fig. 4. Migratory connectivity within the Sanderling population over time. The spatial spread of the population for a given period was calculated as the area of the minimum convex hull enclosing 60\% (grey bars and darkgrey polygon) or $95 \%$ (line bars and light-grey polygons) of the combined MCMC-estimated paths from all 13 individuals. The maps show two extremes: periods of the greatest (left) and least (right) connectivity within the population. The dashed line indicates the boundaries of the Flyway used by the tracked Sanderlings.

regions, was generally underestimated using leg-flag resightings, and even omitted when relying on count data. Strikingly, the coasts of central and southern Japan were prominent in the count data for both migration legs, and for southward migration in the leg-flag resightings, yet only one of the tracked Sanderlings (B013) showed a migration route via Japan.

Clearly, all methods discussed here have limitations and some of the discrepancies between the count data and the other three methods may be partly explained by the fact that we obtained tracking data from a small number of individuals from a single wintering population only. Additional tracking data would undoubtedly improve the accuracy of our estimates, but leg-flag resightings from Sanderlings caught and flagged at other wintering sites along the EAAF show very similar spatial patterns to the individuals flagged in South Australia (Minton 
et al. 2011). Finally, the count data presumably include individuals from several wintering populations, and yet key sites used by our tracked individuals were not recorded in these data. Those sites might not have been counted or do not appear in Bamford et al. (2008) for other reasons, such as the counts may have been too small to meet the $1 \%$ of the Flyway population criterion. We also recognise that studies of population counts and leg-flag resightings are primarily intended for purposes other than identifying crucial areas for conservation, including the study of population dynamics and estimating mortality rates. However, these data resources constitute the most extensive information on species-specific movements and are therefore frequently used to identify areas of importance and to inform conservation planning. The discrepancy between counts, legflag resightings and individual movement data shown here highlights the value of integrating multiple data sources in order to inform conservation planning, determining priorities and resource allocation on ground.

\section{Geolocator analysis}

The correspondence between both geolocator methods used here is initially surprising, given the low precision and accuracy of the simple threshold method (Lisovski et al. 2012). However, most shorebird species have a preference for open habitats, resulting in little noise in light-intensity recordings. Moreover, the equinoxes - periods with comparatively low accuracy and precision in the simple threshold estimates (Lisovski et al. 2012)did not coincide with periods in which the Sanderlings visited the five important foraging or resting areas. The two methods might thus yield very different results in other species, especially in those using more vegetated or heterogeneous habitats. Additionally the MCMC path estimates feature important advantages over the simple threshold estimates in that the Bayesian method provides a framework that enables additional information, such as species-specific habitat preferences, movement behaviour and home-ranges, to be incorporated. This greatly reduces the probability of erroneous, incompatible location estimates. Moreover, the method allows estimation of confidence intervals for location estimates that reflect the quality of the data. Finally, the method permits the estimation of a continuous path, whereby each observation is used and evaluated in relation to all other observations, rather than the rather arbitrary qualification of each position in isolation and hence the potential omission or inclusion of positions derived by simple threshold estimates (Sumner et al. 2009).

Our template-fit analysis allowed for the breeding areas of the tracked Sanderlings to be identified (Fig. 1). Supporting the analysis, the 100\%- and 99\%-likelihood contour lines for the individual breeding areas showed identifiable and concurrent minima on or close to locations on land (for more details, see supplementary material S2). Six individuals migrated and probably bred on the New Siberian Islands, well known as an area of breeding shorebirds, including Sanderlings (Lappo et al. 2012). The breeding locations of two individuals were estimated to be just below the New Siberian Islands in the coastal Siberian mainland. Although Sanderlings are not recorded as breeding in this area (Lappo et al. 2012), it should to be noted that based on our template-fit analysis, locations on the Islands are equally likely and are well within the latitudinal accuracy of the position estimates. The location estimates for the remaining five individuals were west of the New Siberian Islands, as far as the eastern part of Taimyr Peninsula (Fig. 2). Both the eastern coastal areas of Taimyr Peninsula and the Lena Delta are confirmed breeding areas of Sanderlings (Lappo et al. 2012).

The rapid and highly-synchronised northward migration of Sanderlings (Fig. 3) concurs with other observations on migratory birds (reviewed by Nilsson et al. 2013). In fact, the tracked population spent twice as long on southward migration as northward migration. Such patterns are thought to be related to high selection pressure on a timely arrival at the breeding grounds (e.g. McNamara et al. 1998; Kokko 1999; Both and Visser 2001) with northward migration therefore considered a period of considerable time constraint. Similarly, the migratory connectivity within the population varied over time and between the two migration legs. As a result of the highly synchronised northward migration, the area used by the population shrank by an order of magnitude once all individuals arrived on the central Asian coastline (Fig. 4b). In contrast, spatial connectivity was very low during southward migration, to the extent that as some Sanderlings arrived at wintering sites in South Australia others had only just arrived at the Yellow Sea, lagging $\sim 9000 \mathrm{~km}$ behind (Fig. 4c).

We observed no differences between males and females in their timing of northward migration. However, the schedule of departure from the breeding grounds seemed to be sex-specific. All males left within a short time period (within 14 days of one another), whereas all but one female left later, after the last male, and with considerably more variation between individuals (Fig. 2c). Although very little is known about sex-specific parental investment in Sanderlings, Tomkovich and Soloviev (2001) and Reneerkens et al. (2014) observed that only single birds cared for hatchlings and that more males attended broods from earlier clutches, whereas females predominantly cared for late clutches. This could explain our observed differences in departure dates between the sexes and suggests that some females may have had two clutches, as observed in other areas (Reneerkens et al. 2009), with females caring for the second clutch.

During northward migration, Sanderlings made an initial, long, migratory flight across the Equator, after which they all made three to five stops before crossing the Arctic Circle and arriving at their breeding grounds. In contrast, most Sanderlings used as many as six or seven stops during southward migration. This hopping between sites during southward migration and the latter stage of northward migration is similar to that observed in Ruddy Turnstones (Minton et al. 2010) but contrasts with what we know from tracking studies of other species within the EAAF (Driscoll and Ueta 2002; Battley et al. 2012; Minton et al. 2010, 2013). These other species (Bar-tailed Godwit (Limosa lapponica), Greater Sand Plover (Chardrius leschenaultia) and Eastern Curlew (Numenius madagascariensis)) use one or two major stopover sites during both northward and southward migrations. Sanderlings and Ruddy Turnstones are generalist feeders (Piersma et al. 1996) and may thus be less restricted in their habitat use than the other species. Alternatively, the rather high number of stops observed in Sanderlings and Ruddy Turnstones may be related to their body size (cf. Piersma 1987; 
Warnock 2010), both species being among the smallest species tracked within the EAAF thus far.

\section{Conclusions}

Given the apparent value of integrating tracking studies with existing leg-flag resightings and count data to identify crucial areas for conservation, we urgently require more detailed individual migration tracks for the entire range of migratory shorebird species and populations using the EAAF. Study designs should emphasise acquisition of sufficient individual tracks to infer distributions both within and between populations throughout the migration period. Increased understanding of how species and populations use the network of sites along the Flyway would also assist predictions of how shorebirds are likely to respond to the rapid changes to their habitats within the Flyway. Tracking studies, combined with the systematic monitoring of the population through marking, resighting and counting, therefore form an essential part of the empirical research fundamental to conserving the many threatened migratory populations in the EAAF and elsewhere in the world.

\section{Acknowledgements}

We would like to thank the late Ren de Garais who (together with Ian D. Steward) first drew our attention to the presence of Sanderlingswith leg-flags on the shores of the south-eastern coast of South Australia. We also thank all members of the Victorian Wader Study Group (VWSG) for deploying and retrieving geolocators from Sanderlings. We specifically thank Roger Standen for providing the leg-flag resightings of Sanderlings, and Simon Wotherspoon and Michael Sumner for their work on the SGAT software (Wotherspoon et al. 2013) and their support in the analyses. Heiko Schmaljohann and Theunis Piersma provided valuable comments on a former draft of the manuscript. Several individuals and organisations, notably the Norman Wettenhall Foundation, provided funding to the VWSG to conduct this geolocator project. Friends of Shorebirds South East also raised significant funding to pay for geolocators. Banding permits were supplied by the Australian Bird and Bat Banding Scheme, Canberra. Animal ethics (D0001404067) and state approvals to undertake scientific research (M23554-24) were provided by the South Australian authorities.

\section{References}

Alerstam, T., Hedenström, A., and Åkesson, S. (2003). Long-distance migration: evolution and determinants. Oikos 103, 247-260. doi:10.1034/ j.1600-0706.2003.12559.x

Amano, T., Szekely, T., Koyama, K., Amano, H., and Sutherland, W. J. (2010). A framework for monitoring the status of populations: an example from wader populations in the East Asian-Australasian Flyway. Biological Conservation 143, 2238-2247. doi:10.1016/j.biocon.2010.06.010

Bamford, M., Watkins, D., Bancroft, W., Tischler, G., and Wahl, J. (2008). Migratory shorebirds of the East Asian-Australasian Flyway: population estimates and internationally important sites. Available at http://www. environment.gov.au/resource/migratory-shorebirds-east-asian-australasian-flyway-population-estimates-and [Verified 8 February 2016].

Battley, P. F., Warnock, N., Tibbitts, T. L., Gill, R. E., Piersma, T., Hassell, C. J., Douglas, D. C., Mulcahy, D. M., Gartrell, B. D., Schuckard, R., Melville, D. S., and Riegen, A. C. (2012). Contrasting extreme longdistance migration patterns in Bar-tailed Godwits Limosa lapponica. Journal of Avian Biology 43, 21-32. doi:10.1111/j.1600-048X.2011. 05473.x

Bauer, S., Lisovski, S., and Hahn, S. (2015). Timing is crucial for consequences of migratory connectivity. Oikos [Online]. doi:10.1111/oik.02706
Both, C., and Visser, M. E. (2001). Adjustment to climate change is constrained by arrival date in a long-distance migrant bird. Nature 411, 296-298. doi:10.1038/35077063

Bridge, E. S., Thorup, K., Bowlin, M. S., Chilson, P. B., Diehl, R. H., Fleron, R. W., Hartl, P., Kays, R., Kelly, J. F., Robinson, W. D., and Wikelski, M. (2011). Technology on the move: recent and forthcoming innovations for tracking migratory birds. Bioscience 61, 689-698. doi:10.1525/ bio.2011.61.9.7

Calenge, C. (2006). The package 'adehabitat' for the R software: a tool for the analysis of space and habitat use by animals. Ecological Modelling 197, 516-519. doi:10.1016/j.ecolmodel.2006.03.017

Colwell, M. A. (2010). 'Shorebird Ecology, Conservation and Management.' (University of California Press: Los Angeles, CA.)

Conklin, J. R., Battley, P. F., Potter, M. A., and Fox, J. W. (2010). Breeding latitude drives individual schedules in a trans-hemispheric migrant bird. Nature Communications 1, 67.

Dingle, H., and Drake, V. A. (2007). What is migration? Bioscience 57, 113-121. doi:10.1641/B570206

Driscoll, P. V., and Ueta, M. (2002). The migration route and behaviour of Eastern Curlews Numenius madagascariensis. Ibis 144, E119-E130. doi:10.1046/j.1474-919X.2002.00081.x

Fauchald, P., and Tveraa, T. (2003). Using first-passage time in the analysis of area-restricted search and habitat selection. Ecology 84, 282-288. doi:10.1890/0012-9658(2003)084[0282:UFPTIT]2.0.CO;2

Gill, R. E., Tibbitts, T. L., Douglas, D. C., Handel, C. M., Mulcahy, D. M., Gottschalck, J. C., Warnock, N., McCaffery, B. J., Battley, P. F., and Piersma, T. (2009). Extreme endurance flights by landbirds crossing the Pacific Ocean: ecological corridor rather than barrier? Proceedings of the Royal Society B: Biological Sciences 276, 447-457. doi:10.1098/ rspb.2008.1142

Griffiths, R., Double, M. C., Orr, K., and Dawson, R. J. G. (1998). A DNA test to sex most birds. Molecular Ecology 7, 1071-1075. doi:10.1046/ j.1365-294x.1998.00389.x

Harrington, B. A. (2001). Red Knot (Calidris canutus). In 'The Birds of North America', no. 563. (Eds A. Poole and F. Gill.) pp. 1-32. (The Birds of North America, Inc.: Philadelphia, PA.)

Holdo, R. M., and Roach, R. R. (2013). Inferring animal population distributions from individual tracking data: theoretical insights and potential pitfalls. Journal of Animal Ecology 82, 175-181. doi:10.1111/j.13652656.2012.02031.x

Kirby, J. S., Stattersfield, A. J., Butchart, S. H. M., Evans, M. I., Grimmett, R. F. A., Jones, V. R., O'Sullivan, J., Tucker, G. M., and Newton, I. (2008). Key conservation issues for migratory land- and waterbird species on the world's major flyways. Bird Conservation International 18, S49-S73. doi:10.1017/S0959270908000439

Kokko, H. (1999). Competition for early arrival in migratory birds. Journal of Animal Ecology 68, 940-950. doi:10.1046/j.1365-2656.1999.00343.x

Lanting, F. (1984). Sanderlings, globe trotting shorebirds of the Pacific. Pacific Discovery 37, 9-14.

Lappo, E. G., Tomkovich, P. S., and Syroechkovskiy, E. (2012). 'Atlas of Breeding Waders in the Russian Arctic.' (Institute of Geography, Russian Academy of Sciences: Moscow, Russia.)

Lisovski, S., and Hahn, S. (2012). GeoLight - processing and analysing lightbased geolocator data in R. Methods in Ecology and Evolution 3, 1055-1059. doi:10.1111/j.2041-210X.2012.00248.x

Lisovski, S., Hewson, C. M., Klaassen, R. H. G., Korner-Nievergelt, F., Kristensen, M. W., and Hahn, S. (2012). Geolocation by light: accuracy and precision affected by environmental factors. Methods in Ecology and Evolution 3, 603-612. doi:10.1111/j.2041-210X.2012.00185.x

MacWhirter, B. P., Austin-Smith, P., Jr, and Kroodsma, D. E. (2002). Sanderling (Calidris alba). In 'The Birds of North America', no. 653. (Eds A. Poole and F. Gill.) (The Birds of North America Online: Ithaca, NY.) McKinnon, L., Smith, P. A., Nol, E., Martin, J. L., Doyle, F. I., Abraham, K. F., Gilchrist, H. G., Morrison, R. I. G., and Bety, J. (2010). Lower predation 
risk for migratory birds at high latitudes. Science 327, 326-327. doi:10.1126/science.1183010

McNamara, J. M., Welham, R. K., and Houston, A. I. (1998). The timing of migration within the context of an annual routine. Journal of Avian Biology 29, 416-423. doi:10.2307/3677160

Minton, C., Gosbell, K., Johns, P., Fox, J. W., and Afanasyev, V. (2010). Initial results from light level geolocator trials on Ruddy Turnstone Arenaria interpres reveal unexpected migration route. Wader Study Group Bulletin 117, 9-14.

Minton, C., Wahl, J., Gibbs, H., Jessop, R., Hassell, C., and Boyle, A. (2011). Recoveries and flag sightings of waders which spend the non-breeding season in Australia. Stilt 50, 17-43.

Minton, C., Gosbell, K., Johns, P., Christie, M., Klaassen, M., Hassell, C., Boyle, A., Jessop, R., and Fox, J. (2013). New insights from geolocators deployed on waders in Australia. Wader Study Group Bulletin 120,37-46.

Niles, L. J., Burger, J., Porter, R. R., Dey, A. D., Minton, C. D. T., Gonzales, P. M., Baker, A. J., Fox, J. W., and Gordon, C. (2010). First results using light level geolocators to track Red Knots in the Western Hemisphere show rapid and long intercontinental flights and new details of migration pathways. Wader Study Group Bulletin 117, 123-130.

Nilsson, C., Klaassen, R. H. G., and Alerstam, T. (2013). Differences in speed and duration of bird migration between spring and autumn. American Naturalist 181, 837-845. doi:10.1086/670335

Pennycuick, C. J., Åkesson, S., and Hedenström, A. (2013). Air speeds of migrating birds observed by ornithodolite and compared with predictions from flight theory. Journal of the Royal Society: Interface 10, 20130419. doi:10.1098/rsif.2013.0419

Piersma, T. (1987). Hop, skip or jump? Constraints on migration of Arctic waders by feeding, fattening, and flight speed. Limosa 60, 185-194.

Piersma, T., van Gils, J., and Wiersma, P. (1996) Family Scolopacidae (snipes, sandpipers and phalaropes). In 'Handbook of the Birds of the World. Vol. 3: Hoatzin to Auks.' (Eds J. del Hoyo, A. Elliott and J. Sargatal) pp. 444-533. (Lynx Edicions: Barcelona.)

Piersma, T., and Baker, A. J. (2000). 'Life history characteristics and the conservation of migratory shorebirds. In 'Behaviour and Conservation'.
(Eds L. M. Gosling and W. J. Sutherland). pp. 104-124. (Cambridge University Press: Cambridge, UK.)

Ramsar Convention Bureau (1971). Convention on wetlands of international importance especially as waterfowl habitat 1971. Available at http:// portal.unesco.org/en/ev.php-URL_ID=15398\&URL_DO=DO_TOPIC\& URL_SECTION=201.html [Verified 8 February 2016].

Reneerkens, J., Benhoussa, A., Boland, H., Collier, M., Grond, K., Gunther, K., Hallgrimsson, G.T., Hansen, J., Meissner, W., de Meulenaer, B., Ntiamoa-Baidu, Y., Piersma, T., Poot, M., van Roomen, M., Summers, R. W., Tomkovich, P.S., and Underhill, L.G. (2009). Sanderling using African-Eurasian flyways: a review of current knowledge. Wader Study Group Bulletin 116, 2-20.

Reneerkens, J., van Veelen, P., van der Velde, M., Luttikhuizen, P., and Piersma, T. (2014). Within-population variation in mating system and parental care patterns in the Sanderling (Calidris alba) in northeast Greenland. Auk 131, 235-247. doi:10.1642/AUK-13-247.1

Runge, C. A., Martin, T. G., Possingham, H. P., Willis, S. G., and Fuller, R. A. (2014). Conserving mobile species. Frontiers in Ecology and the Environment 12, 395-402. doi:10.1890/130237

Sumner, M. D., Wotherspoon, S. J., and Hindell, M. A. (2009). Bayesian estimation of animal movement from archival and satellite tags. PLoS One 4, e7324. doi:10.1371/journal.pone.0007324

Tomkovich, P. S., and Soloviev, M. Y. (2001). Social organisation of Sanderlings breeding at northern Taimyr, Siberia. Ornithologia (Moscow) 29, 125-136.

Warnock, N. (2010). Stopping vs. staging: the difference between a hop and a jump. Journal of Avian Biology 41, 621-626. doi:10.1111/j.1600048X.2010.05155.X

Wilcove, D. S., and Wikelski, M. (2008). Going, going, gone: is animal migration disappearing? PLoS Biology 6, e188. doi:10.1371/journal.pbio. 0060188

Wotherspoon, S.J., Sumner, M.D., and Lisovski, S. (2013). R package SGAT: solar/satellite geolocation for animal tracking. GitHub repository, available at https://github.com/SWotherspoon/SGAT [Verified 15 January 2016]. 